\title{
Re-bordering Immigrant and Refugee Identities in Quebec's Multicultural Society: the case of South Asian (SA) youth
}

\author{
Ratna Ghosh (McGill University) \\ Jaswant Guzder (McGill University)
}

\begin{abstract}
Re-bordering is an aspect of globalization. Borders have become impervious to national, political and even cultural boundaries. All regions of the world are permeable to political, economic, cultural, social, environmental and epidemic factors. People's identities and identifications are no longer seen as being stable and fixed, but rather- they are constantly in a state of flux

Canada is a country of immigrants and the last census (2006) put the number of visible minority people at $16.20 \%$ of a population of nearly 34 million people (Statistics Canada, 2007). Canada is known as a country with a broad immigration policy and one of the top destinations for immigrants. Canada is also seen as a leader in refugee protection and ranks first among the G8 major industrialized countries in the number of refugee status claimants per capita of its population. In 2001, the Immigration Act of 1976 was replaced by the Immigration and Refugee Protection Act (IRPA) (Bill-11), at which point Canada began to accept approximately 25,000 refugees a year. OECD figures indicate that in 2008, 34,800 people sought asylum in Canada.
\end{abstract}

Since $9 / 11$ there has been a significant change in how cultural and religious minorities, especially those from certain parts of the world, are viewed. People from South Asia ${ }^{1}$ more if they are identifiable as Muslims - are viewed with suspicion. Globalization and international migration, as well as refugees from the wars in Afghanistan and Sri Lanka ${ }^{2}$ have been bringing people from the sub-continent of India to Western countries in larger numbers than ever before.

South Asians (SAs) are the largest source of immigration in Canada, and in fact, one of the fastest growing immigrant groups in North America. This trend is not likely to change given the need for immigrants for a graying population and a below sustainable birthrate. Many SAs come to Quebec which has around 80,000 people with origins in the sub-continent, and they are mainly concentrated in Montreal.

\begin{abstract}
Résumé
"Retracer les frontières" est un aspect de la globalisation. A travers les frontières, les bornes nationales, politiques et même culturelles sont devenues imperméables. Toutes les régions du monde sont perméables aux facteurs politiques, économiques, culturels, sociaux, environnementaux et épidémiques. Les notions d'identités et d'identifications du genre humain ne sont, désormais, plus considérées comme étant stables et fixes, mais plutôt sont-elles constamment en état de fluctuation.

Le Canada est un pays d'immigrants, et le dernier recensement (2006) a avancé le nombre des minorités visibles à $16,20 \%$ d'une population de près de 34 millions d'habitants (Statistics Canada, 2007). Le Canada est reconnu comme un pays ayant une vaste politique migratoire et est l'une des destinations préférées des immigrants. Le Canada est également perçu comme un leader dans la protection des réfugiés et occupe la première place parmi les grands pays industrialisés du G8, dans
\end{abstract}

\footnotetext{
${ }^{1}$ South Asia refers to the sub-continent of India which remains a multicultural, multi-religious region even after the partition of India in 1947 into India and Pakistan and later Bangladesh, The region also includes Sri Lanka, Nepal, Bhutan, and Afghanistan is also included.

${ }^{2}$ Although the 30 year war ended in the defeat of the Tamil Tigers on May 18, 2009, hundreds of thousands of Tamil people were displaced and fled as refugees to many parts of the world as refugees. On August 13, 2010, 492 Tamil asylum seekers arrived in Vancouver by ship. But their claims are under consideration at this point.
} 
le nombre des revendicateurs du statut de réfugié et par habitant dans sa population. En 2001, la Loi sur l'Immigration de 1976 a été remplacée par la Loi sur l'Immigration et la Protection des Réfugiés (LIPR) (Projet de loi-11), à un tel point que le Canada a commencé à accepter environs 25000 réfugiés par an. Les données de l'OECD indiquent qu'en 2008, 34800 personnes ont cherché asile au Canada.

Depuis le 11 Septembre, un changement significatif a été constaté dans la manière dont les minorités culturelles et religieuses, particulièrement celles qui proviennent de certaines parties du monde, sont perçues. Les habitants d'Asie du Sud, davantage s'ils sont Musulmans, sont regardés avec suspicion. La globalisation et la migration internationale, ainsi que les réfugiés des guerres en Afghanistan et au Sri Lanka, ont entraîné des gens en plus grand nombre que jamais, du souscontinent de l'Inde vers les pays occidentaux.

Les Sud-Asiatiques (SA) représentent la source la plus importante de l'immigration canadienne, et en fait, l'un des groupes d'immigrants à la croissance rapide, en Amérique du Nord. Cette tendance n'est pas susceptible de changer, compte tenu de la nécessité des immigrants pour compenser à une population vieillissante et à un taux de naissance en dessous de la moyenne. Beaucoup de SA vont au Québec qui compte environ 80000 habitants originaires du sous-continent, et ils sont principalement concentrés à Montréal.

\section{THEORETICAL FRAMEWORK}

This study consists of data from two empirical investigations. It is part of a larger study on "Schools, Culture and Mental Health: a society in transformation" with funds from the Fonds de la recherche en santé of the Quebec Government (FRSQ).

The design of the study is an integrative theoretical framework based on postmodern, postcolonial and cultural theories to explore educational experiences. In addition, the Location of Culture, the stress-health model and intergenerational conflict theory are used to explain mental health issues. Postmodernists have argued that knowledge is a consequence of identity and social location. Bhabha (1990) points out that not only are difference and otherness created but that ambivalence is produced and in-between groups emerge. Concepts of difference, ambivalence and hybridity exist at the borderlines and postcolonial migrants challenge binary categories and traditional identities of the host and other by their transcultural lives which simultaneously belong to the East and West. Cultural theory explains the nature of culture and its implications for social life (Smith and Riley, 2009). Cultural institutions such as education systems affect students' lived experiences with implications for their identities and life chances. Winnicott (1967) discusses the Location of Culture as constantly evolving and located neither completely in an internal location nor completely externally, but rather "in-between" (Guzder, 2010).

Mental and psychological well-being is examined through the stresshealth model which sees acculturative stress as a risk factor and coping resources and strategies as resource factors (Ensel and Lin, 2000). Studies have linked the immigrant experience (especially the stress factor) and increase in levels of 
mental health problems (e.g. depression) (Yeh and Inose, 2002). Personal strategies and resources, along with social resources, can predict an individual's mental health outcome (Jibeen and Khalid, 2010).

For mental health, we also looked at intergenerational conflict theory, which addresses adjustment problems such as intergenerational gap and adolescent identity crisis from cultural conflict. The gap in cultural values results in intergenerational gaps which in turn lead to weakened parental control which is very important for South Asian parents.

Following this integrated theoretical perspective, the overall goal of this study was to focus on representational space (students' lived experiences with regard to educational and mental health issues).

\section{IMMIGRANTS OF COLOUR}

In Europe, Singla (2005) points out, the discussion about minorities and migrants is based on geographical categories. She quotes Palumbo Liu (1999): "From the point of view of racism, there is no exterior, there are no people on the outside. There are only people who should be like us, and whose crime it is not to be." This view does not recognize people outside the centre. Discourse about minorities in North America is based on creating borders. In English-speaking immigrant countries, especially in North America, the discourse on minorities is relational and based on centre and periphery because concepts of racism/discrimination, ethnicity /culture, exclusion/inclusion are all based on the construction of bordering and re-bordering (when the targets of discrimination change). Borders create the Other and are drawn on the basis of "differences" in religion, language, ethnicity (skin colour), cultural practices and social ideology. The borders keep some people in while the Other who is "different" is kept out. In school, experiences of children of South Asian background being constructed as the Other greatly affects their identities as well as their affiliation to the host culture and has an impact on their mental well being.

South Asian students are "different" from the mainstream Canadians of European cultures that speak French (and English) and are largely Christians. Their differences are due to their ethnicity, culture, linguistic ability and religion (hey are mainly Hindus and Muslims). They also come from traditional cultures and face Western cultural norms they are not familiar with, especially if they are from rural and semi-urban backgrounds. For children the clash of home and school cultures can cause conflict. In addition, experiences of racism/discrimination and exclusion based on ethnicity/culture/religion in schools and in the North American society are contrary to the principle that "all human beings have equal value and should not be given a demeaning picture of 
themselves through the school curriculum and school environment" (Ghosh: 2002, 3). Racism can be overt or covert and is expressed in various ways. As Charles Taylor points out: "Non-recognition and misrecognition can inflict harm, can be a form of oppression, imprisoning someone in a false, distorted, and reduced mode of being " (Taylor: 1992, 25). As forms of oppression, Othering and non-recognition influence the development of self-concept and the construction of identity.

There are many classifications that can be used to study the degree of satisfaction with the school and one's mental well-being. One such classification by John Berry is based on identification with the host culture. Several empirical studies using this model show validity from a number of theoretical perspectives. For example, basing their study of cultural identity, acculturation and mental health on John Berry's typology of identities, Bhui et al (2005) assessed mental health problems of adolescents from ethnic groups in Britain. They found that cultural integration (e.g. factors such as clothing and friendship choices) leads to lower levels of adolescent mental health problems, whereas segregation and marginalization indicated increased risk of mental health problems.

Berry's model classifies people on weak and strong affiliation with the host culture and the culture of origin on a number of independent dimensions. First, there is the group that rejects the culture of the host (or majority culture in the host country) so as to maintain their traditional culture resulting in segregation or traditionalism. Some first generation immigrants attempt to preserve their traditions and culture in their children. They live in the host country in ethnic ghettos, work in factories which are ghettoized linguistically, and maintain close ties with the home country which is facilitated by globalization. Communications technology and the internet make frequent communications with relatives and friends in the home country increasingly easy with inexpensive telephone packages and software like Skype.

Some others prefer the host culture over their own culture in an effort to get assimilated. They feel that since they have to work, compete and live in this culture they want their children to shed ways of their home country so that they can be "Canadian". The danger here is that while they want to be "Canadian", people in the host country may not think of them as Canadians. This is especially true for visible minorities who despite being born here are often treated as foreigners or visitors (Ghosh, 2000). Alternatively, both sets of behaviours and attitudes may be rejected resulting in a marginalized identity.

The fourth type is a more flexible possibility where people adopt or choose attitudes and behaviours from both cultures. This bi-cultural or integrated 
identity retains some of the values and customs of the traditional culture and blends them with certain values of the host culture.

Since identities change, this typology should not be seen as a linear model but one in which affiliations change back and forth and sometimes coexist. However, given that identities are multiple and constantly changing, there is a need to rethink our assumptions of culture and identity from a dualistic position to a re-bordered sense of us/and them. Bifurcated cultures are oversimplified and essentialized. We require a more critical perspective than the us/them or either/or subject positions. So, while there is a need to acknowledge and negotiate borders there is also the possibility of a rebordered space- a third space (Bhabha, 1994).

We look at a transnational identity. Transnationalism is understood here as the "process by which immigrants develop and maintain the social relations that link their original and adopted countries together" (Glick, Schiller, Baach and Blanc-Szanton,1992). They participate in the society they live in but maintain close links with the home they came from. In an age of globalization, the availability of travel and telecommunications makes it possible for people to be transnationals by maintaining close ties with the home country, if not travelling frequently, certainly by internet and very inexpensive international telephone plans which are increasingly being made available.

Transnationalism can be seen as a more globalized form of integration made possible with communications technology. This concept leaves room for bordering and re-bordering, shaping and re-shaping people's pre-immigration values and reinterpreting them in the context of their post-immigration experiences. Herein comes Homi Bhaba's concept of the Third Space where a hybrid identity is positioned within this third space. It is a form of "inbetweenness" straddling two cultures. As transcultural people they are able to transverse both cultures and to translate, negotiate and mediate affinity and difference within a dynamic of exchange and inclusion.

The few studies (Levitt: 2004) linking transnationalism to mental health indicate that the fact that people do not need to choose between traditionalism and assimilation when they live transnational lives causes less emotional and psychological stress of having moved away from close relatives and friends. They reduce acculturative stress that influences their psychological status (Bhattacharya: 2008).

\section{THE CONTEXT}

South Asians (SAs) have a common history and common cultural roots although there is an immense amount of diversity in terms of language, religion and 
economic status. While people from India belong to every religion, there is a sizable Sikh population in Canada (they were the first immigrants to Canada); South Asian Muslims from Afghanistan, Pakistan and Bangladesh, along with a considerable number of Hindu's from Bangladesh, who are also seeking refugee status. Refugees from Sri Lanka are largely Tamil Hindus although there are some Muslims and Christians. Ignorance of South Asian religions and cultures (especially in schools) in Western countries complicates and makes their interaction in society more difficult, and they are all potentially in danger of being stereotyped as "terrorists".

Despite Canada's federal Multicultural Policy (1972) and Act, (1988), there is not a common response to policy and practice in the provinces. The province of Quebec does not subscribe to the federal policy of Multiculturalism and has French as the official language. However, in Montreal which is Quebec's largest city, with 46.4 percent of the student population consisting of first or second generation children of immigrants, Quebec's emerging “cultural communities" 3 have fundamentally transformed the traditionally homogenous French-language school sector. This diverse population is concentrated in the Greater Montreal region which is no longer a bi-cultural (French and English), and largely Catholic city although the rest of the province remains largely homogeneous, French-speaking and Catholic. The issue of diversity is further complicated by language legislation which made French the language of instruction in schools and employment since 1977 (Bill 101). SAs are a small minority in Quebec and due to their colonial history they are more familiar with English (if they know a foreign language). The barriers in education and employment are exacerbated by the French language requirement for those to whom French is an unfamiliar language.

From the point of view of the host country the social institutions are a significant means of integrating immigrants into their society. The school is perhaps the main instrument for socialization into the culture of the host society. In Quebec, the public schools have focused largely on language training and "welcome classes" (classes d'acceuil) to integrate non-French speaking students into the system. Although Quebec is the only province with "welcoming classes" it nonetheless puts the onus of integration on the students and their families because the system itself did not make any functional or structural changes to welcome the student into the school culture. McAndrew (2003) points out that the focus in Quebec has shifted from intercultural education to citizenship

\footnotetext{
${ }^{3}$ Ethno-cultural groups are referred to as "cultural communities" in Quebec. The Federal government uses the term "visible minorities" for ethno-cultural groups of colour.
} 
education and future public discourse is likely to focus on services for students rather than programs for intercultural understanding.

From the point of view of the immigrant student population, scholars have pointed to the impact of the social and psychological dislocations of migration to Western countries from non-European cultures. Cultural, religious and psychological identities are being constantly challenged because people are now face to face with different practices and spaces are changing. This is particularly true with immigrants and refugees who come from countries of the South because they are often faced with radically different value systems and languages. Their children face clashes of borders (home and school cultures, differences in religion, language and behavior patterns) and undefined spaces which cause psychological and mental conflicts. The processes and dynamics of school life for migrant and refugee youth become more complex with low socioeconomic status (e.g. parent's educational level and linguistic ability), as well as cultural and religious discordance (especially for girls).

The literature on SA students clearly indicates that borders of social class and space make a great difference to their education and achievement. Children of SA professionals have been referred to as a "model minority" (Stanley and Okazaki (1990) especially in studies done in the US. The Canadian 2002 Ethnic Diversity Survey (Statistics Canada, 2003) indicates that children of Chinese and Indian immigrants have higher university completion rates than children of Canadian-born parents, even when demographic and human capital factors are controlled for. Parental human capital and group level economic resources are shown to account for differences in university completion rates. Zhou and Xiong (2005) write that for Asian immigrants in the US, society is highly stratified by class and race so that success "depends disproportionately on family and ethnic community resources, while the failure of some is due largely to low family SES exacerbated by the lack of ethnic community resources" (p.1149). Studies of working class SAs in Britain and also in the US have shown their children to be underachieving and facing conflicts. However, very few youth were accessing or being referred to mental health services or counseling in schools (Messent \& Murell, 2003).

Boyd (2006) found that Chinese, Korean and South Asian second generation youth are doing well economically in the Toronto region which has the largest concentration of SAs in Canada. However, the little research that exists on the SA community in Canada (Wadhwani, 1999; Sharma et al, 2005) paints a bleak picture of the school achievements and mental health of SA youth from working class backgrounds (although anecdotal reports of children of SA professionals indicate high academic performances as in the US). The studies 
show problems ranging from isolation, depression, and anger to aggression and anti-social behavior; from self esteem issues to suicidal ideation. There is a dearth of large-scale data on the SA population, particularly literature on SA students and their experiences in Quebec. Missing from most of the research is an understanding of what life is like for these students. Minority "underachievement" has focused on cultural and linguistic deficits rather than on how youth negotiate their identities in their daily lives. This lack of precise data limits possibilities for developing nuanced and specific policies which are sensitive to special needs of different groups.

Although visible minority youth are more likely to participate in post secondary education (Gluszynski, 2007) in Canada, studies have shown the negative impact on education of low family incomes, systemic discrimination and problems associated with having a first language other than English or French (Taylor and Krahn, 2005). While SA cultures generally value education highly, literature on academic achievement of students from these groups shows variation between groups, and studies on Bangladeshi students consistently indicate low academic achievement (Haque, 2000).

This paper discusses the experiences of two groups of SA youth in a low socio-economic neighbourhood in Montreal. The dropout rate from high school in Quebec is among the highest in the country at 30\%. Students spend a large part of their daily lives in schools. Studies of their school experiences are aimed at making their lives better as well as rescuing them from a life of eventual poverty if they dropout because they experience exclusion, and mental and physical distress on a day to day basis. Those who are achievers may, nonetheless, be subjected to overt and covert forms of discrimination and their school experiences may be equally hurtful (Talbani, 1991). Educational and mental health issues make policy implications significant both for students at risk and for those who succeed in academics. Not only is it important to explore the type and degree of engagement the policymakers (school board, the government and social services) have initiated, but also we need to ask whether the needs of specific groups warrant individual policy approaches for them to overcome barriers and experience equal access and opportunities (OSI, 2010).

This project is a small effort to find out what some of these barriers are in terms of students' educational and mental health. How do students cope with their lives? As the Report of the Action Group on Student Retention says: " a child is at risk when fundamental needs such as identity, stability, safety and justice go unmet" (Report of Action Group, 2010, p.22). Identities are formed and negotiated in relationships: what is the relationship of youth with their parents, their peers, with schools and social service institutions? How do they 
deal with linguistic and cultural issues? How do they cope with problems in school, with their studies? Given that the parents arrive in Quebec with no education or knowledge of French, how do the youth negotiate with cultural institutions such as schools and even other public and health services? Do they seek guidance from school counselors and help from mental health personnel in school?

\section{THE STUDY}

Our study aimed to explore how a few adolescents from two groups of SA students deal with educational and mental health problems and how they are negotiating their needs within the Francophone schools and social services. The goal is to improve their opportunities for full participation in Quebec society while enabling them to develop positive identities based on their culture.

The following research questions formed the basis of the semi-structured interviews:

Assuming that the degree of affiliation impacts the problems faced in school and the mental health of students, the overall question is what is the degree of affiliation to the host and home cultures in the lived daily experiences of the two groups of students??

- How do youth integrate the "two worlds" of parental values and school culture? Inter-generational conflict may have consequences on attitude towards school and affect their educational performance as well as their mental health due to conflicts.

- How do youthdeal with racism especially given that for some, their distinctive Muslim identity can exacerbate their disadvantages (Modood, 1990)? Do they feel marginalized and not recognized?

- If fluency in the language of instruction is a strong predictor for attainment, how do they manage school work especially when parents most often cannot help in French? Does this pose a barrier which affects their school work, home-school relations and ultimately produce stress?

- What is their understanding of mental health? Do they show symptoms of problems in that area?

Two studies have been completed so far. We started with students of Bangladeshi origin because there are no studies specifically on this group in Canada. Studies done in the US and UK indicate problems with their academic achievement as a group as well as with delinquency. The first study was done in a low income area for students of Bangladeshi origin in Montreal, who speak 
Bangla at home. The second study was with students whose parents had come to Canada as refugees from Sri Lanka. They were largely Tamil speaking and lived in the same low income neighbourhood of Montreal but a few of them also lived in the West Island which has a more affluent population. The Bangladeshis were mostly Muslims and the students had all recently come directly from Bangladesh or from another country where they had lived for a brief period of time. Children of Sri Lankan parents were all born in Canada whereas the Bangladeshis were not born in Canada. In both groups, parents did not have any education higher than a high school diploma.. Bangladeshi mothers had very little education and mothers from Sri Lanka had merely high school education. Fathers from both groups had either partially studied in or completed their high school diplomas. Mothers usually did not work and if they did, they were factory workers. Fathers in both groups worked either in factories or restaurants. Sri Lankan parents stressed the point that their own education had been limited by war in their country. In both groups, fathers spoke "broken English" but very little French. Mothers in the Bangladeshi group usually did not speak either English or French while some mothers in the Sri Lankan group spoke a little English. Sri Lankan mothers oversaw the studies of their children and some fathers helped out. but their primary concern was that of their children's education and thus, they had made arrangement to send them to tutoring classes when they themselves could not help in French or in the higher grades.

\section{RESEARCH DESIGN}

Sample: We had 50 students in the Bangladeshi group ( 25 girls and 25 boys) and 48 students in the Sri Lankan group ( 24 girls and 24 boys) between the ages of 13-18. Parents with children aged 13-18 also participated. Subjects were recruited by community workers. The samples were selected on the basis of willingness to participate in the project. For the parents, availability was another factor and for students, movie tickets were given to those who participated in the project.

We used a mixed methods approach by combining quantitative (CBCL, YSR) and qualitative (focus group discussions, survey, semi-structured interviews) for each group. This was based on the need for triangulation of data on the premise that a combination of the two approaches would provide a better understanding of the issues we were exploring.

Focus groups: there were two groups of youth (6-8 girls, 6-8 boys) and two groups of parents (6-8 mothers and 6-8 fathers with children aged 13-18). Focus groups are known to be particularly good for getting data from marginalized groups because participants are given the opportunity to interact 
among themselves and highlight their shared world-views, values and beliefs ( Kitzinger, 1995; Schatzman \& Strauss, 1973).

Questionnaires: 50 Bangladeshi youth ( 25 girls +25 boys $)$ and 48 youth of Sri Lankan parents ( 24 girls +24 boys) were given (1) a survey questionnaire (used in the East Metro Youth Survey done in a Toronto Study and adapted for Quebec). They were also given (2) a standardized Youth Self-Report Form (YSR11-18; Achenbach \& Rescorla, 2001). This form was also given (3) to parents (10 mothers +10 fathers) in the two groups. (4) The Achenbach Child Behaviour Checklist (CBCL 4-16; Achenbach \& Rescorla, 2001) was administered to all students.

Interviews: In-depth semi-structured interviews were conducted with 10 girls and boys and 10 parents as well as two community workers (half in each ethnic group).

\section{FINDINGS}

\section{Negotiating the two worlds}

Although the majority of students indicate good relations with their parents, it is evident that they do not tell their parents much of what is going on either in school or in their lives. Children have imbibed the cultural concept of "saving face" and values of family and collectivism which make them careful about going against their parents openly due to an increased sense of social stigma. Ahmad et al (2009) point out how cultural expectations of silence, subordination and obligation increase SA women's feelings of guilt, shame and social stigma. This is also a contributing factor in keeping them from seeking professional help in abusive situations. Children are socialized into this cultural expectation and behavior.

Canadian schools and society values emphasize individualism and personal freedom. SAs norms of interdependence, sharing and hierarchical relationships lead to conflict situations and limit individualization in youth (Singala: 2005).

In both groups parents are anxious that their children preserve their cultures. They instill the traditional values in their children and want them to be maintained. There are strict rules and guidelines for what they will allow their children to do. These boundaries limit girls more than boys, and girls in both groups are acutely aware of the preferential treatment given to their brothers by their parents. The boundaries relate to going out with peers and mixing with the opposite sex as well as with dress. Food is another issue of contention. In an effort to conform to the majority culture, youth reject their traditional food and want to hang out in fast food joints with their peers. Parents insist that their 
children marry Muslims in the case of Bangladeshis, and Tamil Hindus of the same caste for Sri Lankans.

There is a lot of similarity in the responses of the two groups- both parents and children. Interestingly, most youth report to having good relations with their parents. The children appear to their parents as being "good" and obeying them but parents also know that their children hide things from them. They are made to feel "different" from their peers by their parents and this results in youth not having friends other than in their own ethnic group. For those who do obey their parents, they accept being "different" and do not question their limitations. The conflict for those who do not accept all the limitations (more for boys) is not so much that the youth are trying to break rules but rather that they are not even in a position to argue or fight for what they want.

The parents have come from rural and semi-rural areas in their own countries and seem to be unaware that in their home countries, social norms are changing. In their eyes their children have a lot of freedom and they only want to protect them from the evils of western culture. They are concerned for them and they do not think their children need to hide things from them. They also do not know their children's friends, especially if they are not from the same culture, because the children do not bring their friends home. Parents have caught their children lying.

There is an evident border between the world of home and school. The school world is kept away from parents who rarely communicate with the school. Parents are mainly concerned with grades and there is pressure to get good grades. This is particularly so with the Sri Lankan students. Yet, while they must do well in studies they are not allowed to participate in other school activities. This leads to an intergenerational communication gap and great resentment in children who learn the official languages faster than their parents through schooling and often act as mediators and translators for their parents. This role reversal can lead to conflict in the family (Tyyska, 2008).

\section{SO HOW DO YOUTH DEAL WITH THE CONFLICT OF HOME CULTURE AND SCHOOL CULTURE?}

They exclude their parents from their lives and lead secret lives as several studies have shown (Ghosh 98/99). Even when parents want to create space in which their children could share more, the children choose not to do so. The parents' binary rules of 'can / cannot' do is reformulated by the youth so that they keep seemingly good relations with their parents but secretly go ahead and do things they want to do within limit so as not to be caught. In a few extreme cases they have openly challenged and rejected their parents and joined gangs or run away 
from home. The majority stay within the traditional borders created by the parents (mainly girls), while some (mostly boys) have recreated their borders and developed more culturally integrated lives with host culture friends. A few have rejected their traditional borders completely and moved on to develop new borders within the confines of the host society. There is, of course, the danger of developing marginal identities which can lead to unpredictable and extreme actions.

\section{Dealing with racism}

Students feel that they need "not go through the trouble" of talking to their parents about any problems in school. They either internalize problems or talk with their friends. Hardly anyone in the two groups had gone to see a counsellor or health official with problems they had in school. Bangladeshi youth were called "dirty names" when they first came to Quebec. Bangladeshi female youth experience discrimination based on issues of homosexuality and some regarding clothes such as the "hijab" in school although they tried to distinguish themselves from Pakistanis by not wearing the hijab. On the whole, they are reluctant to express any experiences of racism and a culture of silence keeps them from discussing racist incidences with their parents as well. However, in the CBCL and youth surveys, issues of racism surfaced in the Bangladeshi group. Seven out of 50 students indicated that their greatest concern in school was related to issues of race and acclimatization. Five out of $50(10 \%)$ students indicated that they would like to have classes on how to acclimatize in order to relieve them of stressful situations and 19 out of 50 (38\%) students felt that race was the topmost issue creating stress in their lives.

Students from Sri Lankan families generally feel that they have not faced racism at school. Sri Lankan male youth stated that the majority of their friends are Sri Lankan and that their highschools tended to have a large immigrant population. Therefore, they feel that they do not experience a lot of racism at school. Two 18 year old boys who had started university, however, added that a lot of their engineering professors at university have accents when they speak and often get made fun of. On the CBCL, when students were asked to describe any concerns or problems they have had at school, only one of the 48 students indicated racism as a concern. Similarly, in response to the question about asking students if there is anything that prevents them from doing well in school, only one participant cited racism. In terms of the types of problems they face at school, four students stated that issues relating to race tend to be a concern.

Bangladeshi parents are more forthcoming with comments about the discrimination faced by their children. Fathers are very vocal about bullying 
based on some form of discrimination - one boy was physically attacked while others had their books and valuables stolen: "discrimination is not visible but we can feel it". Repeated bullying had led to alienation and depression and these conditions are aggravated when youth feel that they are unable to share their thoughts and experiences with their parents. Parents' intervention with the school on their behalf has resulted in the school taking some action, but that did not bring the children closer to the parents. Rather, the children rebelled and became defiant but parents could not discipline their children the way they would have in their home countries due to legal restrictions on physical punishment and consequences in Canada. Parents feel frustrated that they cannot penetrate the border between them and their children.

Generally, Sri Lankan mothers and fathers stated that although racism may be a concern in their children's school, "there is nothing you can do about it." In particular, a mother stated that some teachers favor one student over another due to their skin color but that "if you confront the teacher, the child will face more problems." In addition, both mothers and fathers stated that they have faced racism at the workplace and that one's skin color may limit the types of job opportunities one has.

\section{Language and school work}

There is variation in the data on language among the surveys, focus group discussions and interviews. Bangladeshi youth report not having problems with French once they learn the language if they entered school in the lower grades. They learn English from TV and speak their mother-tongue at home. Their frustration is that their parents cannot help them with homework and thus there is a lack of reinforcement of schoolwork at home. Contrary to the interview and focus group data with youth, the survey data on Bangladeshi youth indicate that 11 out of $50(22 \%)$ cite language as the biggest problem and the self report data shows that language barriers are the greatest cause of stress.

Both female and male Sri Lankan youth spoke about the pressure to do well at school from their parents. Most of the male youth stated that they attend English schools and primarily speak English. They all agreed that school is "Ok" and that they receive tutoring if they need additional help. All the boys agreed that their biggest challenges are related to school and the pressures of school.

For parents of both groups, language is clearly a big problem. Mothers report language as the biggest challenge and cause of stress after moving to Quebec. Very aware that they cannot help with homework, they are most frustrated that they cannot understand report cards and have to go to strangers to ask for translations. Letters from school are often translated by the children who 
can be very creative in translating letters and report cards. So, parents therefore want a third person to translate the report cards and letters. They tend to avoid attending parent-teacher meetings because the teachers speak in French. They express disappointment that their children cannot attend English language schools because French language legislation makes it compulsory for children of new immigrants to attend French schools (with very few exceptions). But if possible, they try to help their children by sending them to tutoring classes to learn French and get help with homework. Perhaps having to pay for tutoring classes is an important consideration. The language difference in school further increases the communication gap between the home and school: the "home world" is seen as that of parents, and parents, unable to help with school work, are kept away from their school life. Parents do not understand their children's language - literally and figuratively.

In terms of parent-teacher interviews, the Sri Lankan female youth stated that their fathers tend to attend parent-teacher interviews, although their mothers play an active role in their education at home. Also, Sri Lankan youth stated that they have translated for their parents in the past and that if they need help with homework, they tend to ask their siblings or go to tutoring. Only one boy felt that he was at a disadvantage because his parents were not able to help him with his schoolwork.

On the CBCL, when asked about concerns or problems at school, 8 students mentioned class related difficulties. Similarly, when asked about the problems faced at school, 7 students mentioned class related difficulties.

Parents generally stated that their children's education is very important to them and that their children are doing all right at school. One father stated that when one of his children first came to Canada, he would speak in Tamil in class and his teacher got upset. The teacher asked him not to teach the children Tamil at home. Language was described as an issue by parents. Both mothers and fathers stated that they can communicate somewhat in English, whereas French is a language they have much more difficulty with. Some mothers also expressed disappointment that their children cannot attend English language schools because French language legislation makes it compulsory for children of new immigrants to attend French schools (with very few exceptions) and about the communication gap that this creates between them and their children. Some parents also spoke about needing a translator during parent-teacher interviews and about the embarrassment their children face, as they get older, of having a third party (such as a relative, family friend) translating during these meetings as they are concerned about this third party "knowing their business." 


\section{Mental Health}

Bangladeshi youth have very little understanding of the term mental health. There is also considerable discomfort in discussing the topic. The word "mental" has negative connotations for students and parents alike. They associate it with 'crazy', 'stupid', 'a disease'. They are reluctant to admit discrimination or do not want the stress of negotiating at home with parents about acceptable behavior at school and with friends.

In terms of definitions of mental illness, Sri Lankan male youth defined it as: "retarded, handicapped, and can't do things we can." The boys stated that they do not know anyone with a mental illness. In general, the boys agreed that if faced with an issue, they would mostly go to friends. They would not go see a guidance counsellor since they do not know the person and would not feel comfortable sharing their problem with him/her. In terms of mental health services that might be helpful, the boys stated that getting information to the community about the types of services available and also where to go for psychological help would be useful.

During the in-depth interview with Sri Lankan girls, they stated that they sometimes feel depressed about not having as much freedom as they would like. They feel that their parents do not trust them or recognize their good choices.

On the CBCL, when students were asked about the kinds of help that would be the most useful for SriLankan youth who have stressful problems, 14 out of the 48 participants $(29 \%)$ indicated increased support. In terms of what mental health meant to them, the majority stated responses related to these individuation being a deviation from the norm (12 out of 48 , or $25 \%$ ), it being a brain related issue (11 out of 48 or $29 \%$ ) and that these individuals have mental issues ( 9 out of 48 or $19 \%$ ) and functional difficulties (7 out of 48 or $15 \%$ ).

Bangladeshi mothers think of mental illness as more related to themselves - their anxieties, overprotective nature, being unhappy or depressed. For fathers, mental illness is a byproduct of adjusting to western culture and social systems. They consider these issues as being important for their children's adjustment to school.

Among the Tamil Sri Lankan parent groups, similar to the youth groups, there was general discomfort discussing mental health. They generally stated that although they have heard the term, it is not a familiar one. They also stated that they do not know of anyone with a mental health related issue. Furthermore, although parents agreed that there is stigma in the community with regards to seeking mental health related help, they stated that, if necessary, they would use 
mental health services if that is best for their child but would not tell others that they are seeking these services.

In terms of mental health services that might be helpful, mothers stated that having services where youth can get together and talk will be helpful because children do not always like to listen to their parents. One father stated that basic information about mental health issues through the local newspaper would be helpful. One father also thought that information for older women who stay home might be particularly important. He stated that these women tend to stay at home while their husbands go to work, and their children go to school and thus do not know their language. One father further stated that surveys like this one are helpful.

Studies of SA groups (e.g. SA women) indicate low rates of seeking help from social institutions such as medical, social and legal professions (Ahmad et al, 2009). Data in this study corroborate the hesitancy to seek professional help among SA groups. Furthermore, the data in these studies indicate that girls in both groups get into trouble less than boys do, but that they are more prone to internalization and depression. Patriarchal gender roles in the community and family subject girls to more restrictions, thus silencing them and making them more susceptible to subordination.

Thus, there is a range of views towards mental health in both groups: for parents it is something they need to take into account in the daily lives of their children although none reported any problems. For them good mental health for their children is defined as performing well in school. For the youth it is a disease and they are not aware of the problems and consequences associated with mental health.

Data from both groups in the Youth Self Report (YSR) as well as the CBCL indicate that there is a minority of boys and girls who show borderline/clinical symptoms. The most concerning is the percentage of internalizing, externalizing and total problem scores. The Sri Lankan (SRL) adolescents appear to report a greater percentage of problems overall. Somatic problems are moderately problematic in the SRL group (in the clinical range) but mildly problematic in the Bangladeshi (BND) group. Attention problems and delinquent behavior are moderately problematic in the SRL group but it is not in the borderline range for BNDs. More BND students are withdrawn but anxiety is higher in the SRL group. Unfortunately, we do not have norms for these groups but they seem higher than population rates for Canada. There are more boys than girls who have internalizing and externalizing problems in both groups.

A minority of students of Sri Lankan origin admitted to knowing people who have been in trouble with the police and some who have joined gangs. Gang 
involvement is triggered by a need for protection from racialized violence and socio-economic disadvantage which has a particularly strong correlation with gangs (Wortly, 2009). There are some students in this group, a minority who reported that they either felt like hurting themselves, and a few have tried to hurt themselves; the same number have also felt like killing themselves and three had attempted suicide.. The majority report being well adjusted in school. In the Bangladeshi group a few boys admitted that they had been expelled from school and a community worker who works with the police mentioned several cases of arrests and even teenage pregnancies.

\section{DISCUSSION}

Not only have children and parents faced the challenges of migration to a nonfamiliar culture with linguistic barriers, but their visible minority status creates borders leading to identification of them as being "different", particularly in school. Moreover, being away from extended family and friends socially isolates them especially when parents operate within their rigid traditional patriarchal gendered norms. The juxtaposition of these multiple oppressive experiences simultaneous from society (school) and home (parents) - can cause considerable stress in youth and put them at risk of academic as well as social problems. Parents on the other hand, often suffer considerable loss in status and although they strive for a higher standard of living here than they had in their home countries, they tend to get stuck in low paid factory jobs. Their economic position vis à vis the larger society locates them in a vulnerable place in society. But given their resilience (hard work and ability to do with less) they manage to live better than in their home countries, and maintaining "face" and respect of the family unit within their community here and the extended family in the home country is of great importance to them. That is why they stress good marks for their children so that they can establish themselves in this society through education. Failing and not finishing school is seen negatively but they will not discuss problems, especially psychological ones for fear of losing face in their communities. Social stigma is attached to mental health problems and cannot be discussed. Protection of one's face is highly valued in collectivist cultures such as the SA one.

These two groups of students largely from a low socio-economic area of Montreal either drop out of school or if they finish high school, the majority of them do not continue on for further studies. A study done in 2008 (Statistics Canada, 2008)) based on national representative survey data from Statistics Canada indicates that very large differences exist by national origin groups in university education among children of immigrants in Canada. India has among 
the highest numbers (46\%) in contrast to $23 \%$ among youth of Latin American parents. The fact that some SA students do very well while others do not indicates that cultural capital and socio-economic factors create borders. and within group borders are perhaps as important as those between groups.

The participants of these studies do not show awareness of social services available to them through the school or the Community health centers (CLSCs). Not only is there reluctance to admit problems which prevents them from seeking help, but there is also a stigma attached to doing so in addition to the language problem. There is, therefore, a need for accessible intervention services and language translation.

Studies show that traditionalism reduces the risk of mental disorders (Holman: 2000; Davies: 1998; Escobar: 2000). Perhaps these two groups largely fit into this category. Their ties to the home country through telephone conversations remain at the superficial level and they cannot afford to visit the countries often due to their economic conditions. So, they do not live in both worlds and do not have transnational identities because of economic borders. Rather, youth in these two groups are trying to negotiate the borders at home.

While the borders drawn by parents are a desperate attempt at controlling their children to maintain their cultures, they are fully aware of the need and requirement to redraw borders. Their dilemma is how to give their children opportunities without giving up control. The resulting generational gap for youth who rely and are largely dependent on friends when they have problems indicates stress for both parents and their children. Studies show that integrated friendship choices among Bangladeshi and SA pupils result in lower levels of mental health problems than in white pupils (Bhui et al 2005). In our studies youth did not have friends from other ethnic groups due to the restrictions they faced at home. They were driven to traditional and marginalized friendships. Policy implications are that interventions encouraging integrated friendships should be encouraged and facilitated.

With vulnerable groups it is urgent to address their educational and mental problems at an early stage. There needs to be a better understanding of immigrant and refugee children's early education needs such as linguistic and cultural barriers in accessing early childhood programs especially given that children who come to Canada before the age of 10 seem more likely to integrate into mainstream society and see themselves as part of the host society (Beiser et al, 2005, p.2).

Socio-cultural (language, religion, clothing, behavior patterns), economic and environmental (weather) differences are enhanced by dislocation when people migrate and these factors interrelate to make their situations more 
complex. The mediating role of patriarchy cannot be underestimated and should be directly tackled.

Policy interventions must take a special note of neighborhood conditions- the quality of housing, transportation, access to quality health care, educational and physical facilities, inadequate nutrition and health habits which have a huge impact on children's educational and mental health. SES is a major factor for school achievement and career choice because of the social and cultural capital of the parents. Students from low SES groups cannot draw upon parental resources and networks when needed. Social capital also plays a critical role in the process of integration (Kunz, 2005). Educational opportunities and neighbourhood inequities are rooted in policy decisions and government agencies must work with communities to improve conditions and opportunities for children.

Clearly, another important need for intervention strategies is with respect to the social services provided. The training of culturally competent social workers through community education can change the European/North American bias that continues to be pervasive in the training of health professionals.

Language proficiency in students is absolutely essential but it is not enough. Students need academic tutoring, career counseling, and most importantly, culturally integrated services such as after-school programs, homework and tutoring clubs as well as involvement of the parents.

The hope is that with successive generations the "noise" of the immigration process will die out (Biles \& Lefrance, 2009). Ramji (2008) points out that children of Muslim immigrants, for example, are innovative rather than imitating their parents regarding tradition: "they are individual rather than communitarian" (p.108). The trend towards inter-ethnic partnerships and multiethnic families will dissolve much of the traditional ways of maintaining cultural values, behaviours and attitudes.

Radicalization remains an under-researched area but one way to guard against it is to stress diversity as a source of strength in society. Clearly, Quebec will be a safer place if all groups feel part of a grand "us" rather than a marginalized "them".

This is a limited study because the socio-economic group does not reflect the multifaceted diversity among the SA population altogether, despite the fact that they have common historical experiences. Moreover, the diaspora has developed in different ways in different countries due to the nature of each host society and its immigration policies. Perhaps the largest inequities are in income and educational differentials within the people of South Asia. 


\section{References}

Achenbach, T. M., \& Rescorla, L. A. (2001). Manual for the ASEBA School-Age Forms \& Profiles. Burlington, VT: University of Vermont, Research Center for Children, Youth, \& Families.

Ahmad, F., Driver, N., McNally., M. J., \& Stewart, D. (2009). "Why doesn't she seek help for partner abuse?" An exploratory study with South Asian immigrant women. Social Science and Medicine, 69, 613-622.

Beiser, M., Armstrong, R., Ogilvie, L., Oxman-Martinez. J., \& Rummens. J.A. (2005). The New Canadian Children and Youth Study: Research to fill a gap in Canada's children's agenda. Canadian Diversity/Diversité Canadien. Spring, 21-24.

Bhattacharya, G. (2008). The Indian Diaspora in transnational Context: Social Relations and Cultural Identities of Immigrants to New York City. Journal of Intercultural Studies, 29 (1), 65-80.

Bhabha, H. (1990). DissemiNation: time, narrative, and the margins of the modern nation. In Bhabha (Ed.), Nation and Narration, (291-322). London, UK: Routledge.

Bhabha, H. (1994). The location of culture. London: Routledge.

Bhui, K., Stansfeld, S., Head, J., Haines, M., Hillier,S., Viner, R., \& Booy, R. (2005). Cultural identity, acculturation, and mental health among adolescents in east London's multiethnic community. Journal of Epidemiology and Community Health, 59, 296-302.

Biles, J., \& Lefrance, L. (2009, December). Why Identities Matter: the critical importance of outcome for first and second generation children and youth [PowerPoint slides]. Paper presented at The Conference on Multiple Diversities: Child/Youth identities and life outcomes, Toronto, Ontario. Retrieved from http://www.chsrgevents.ca/shared/PDFs/Biles_Lafrance_presentation_Dec_2009.pdf

Boyd, M. (2006). "The Diversity that Lies within: Second Generation Variations in Socio-Economic Outcomes" Presentation At Metropolis Presents Seminar on Second Generation Experiences, Ottawa, March.

Davies, L.C., \& McKelvey, R. S. (1998). Emotional and behavioural problems and competencies among immigrant and non-immigrant adolescents. Australian and New Zealand Journal of Psychiatry, 32(5) 658-665.

Ensel, W., \& Lin, N. (2000). Age, the Stress Process, and Physical Distress: The Role of Distal Stressors. Journal of Aging and Health, 12(2), 139-168.

Escobar, J. I., Hoyos, N.C., \& Gara M. A. (2000). Immigration and mental health: Mexican Americans in the United States. Harvard Review of Psychiatry, 8 (2) 64-72.

Ghosh, R. (2000). Identity and Social Integration: Girls from a Minority Ethno-Cultural Group in Canada. McGill Journal of Education, 35(3), 279-296.

Ghosh, R. (2002). Redefining Multicultural Education. (2 $2^{\text {nd }}$ ed.). Toronto, Ontario: Nelson Thomas Learning.

Ghosh, R. (April 1998-March 1999). Constructing Identities: The South Asian Experience in North America. The Journal of Women's Studies, 3(1\&2), 127-143.

Glick, S., Basch, N., \& Blanc-Szanton, C. (1992). Transnationalism: A New Analytic Framework for Understanding Migration. Annals of the New York Academy of Sciences, 645(1), 1-24.

Gluszynski, T (2007). Participation in Postsecondary Education: Graduates, Continuers and Drop Outs, Results from YITS Cycle 4. Ottawa: Ministry of Industry, Government of Canada.

Guzder, J. (in press). Second Skins: Family Therapy Agendas of Migration, Identity and Cultural Change. Fokus, Norwegian Journal of Family Therapy.

Haque, Z. (2000).The Ethnic Minority 'Underachieving'Group? Investigating the Claims of 'Underachievement' amongst Bangladeshi Pupils in British Secondary Schools. Race Ethnicity and Education, 3(2), 145-167.

Holman, E. A., Silver, R. C., \& Waitzkin, H. (2000). Traumatic Life Events in Primary Care Patients: A study in an ethnically diverse sample. Archives of Family Medicine, 9, 802-810.

Jibeen, T., \& Khalid, R. (2010). Predictors of Psychological well-being of Pakistani Immigrants in Toronto, Canada. International Journal of Intercultural Relations, 34(5), 452-464.

Kitzinger, J. (1995). Introducing focus groups. British Medical Journal, 311, 299-302.

Kunz, J. L. (2005). "Orienting Newcomers to Canadian Society: Social Capital and Settlement" Thematic

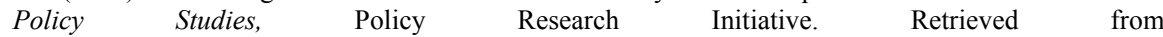
http://www.policyresearch.gc.ca/doclib/SC_Thematic_E.pdf

Levitt, P. (2004).'Transnational Migrants: When 'Home' Means More Than one Country." Retrieved from: http://www.migrationinformation.org/Feature/display.cfm?id=261, March 1, 2010.

McAndrew, M. (2003). Immigration and Diversity: some policy issues confronting the Quebec school system. Policy Options. October, 59-62. Retrieved from http://www.irpp.org/po/archive/oct03/mcandrew.pdf 
Messent, P., \& Murrell, M. (2003). Research Leading to Action: A study of Accessibility of a CAMH Service to Ethnic Minority Families. Child and Adolescent Mental Health, 8 (3): 118-124.

Modood, T. (1990). British Asian Muslims and the Rushdie Affair. Political Quarterly, 61, 143-160.

OECD. (2008). Information Migration Outlook, 2008. Paris: OECD.

(OSI) Open Society Institute. (2010). Muslims in Europe. London, UK: Open Society Foundation.

Ramji, R. (2008). "Creating a Genuine Islam: Second Generation Muslims Growing Up in Canada" Canadian Diversity, 6 (2), 104-109.

Report of the Action Group on Student Retention and Success in Quebec. (2010). Knowledge is Power. Retrieved from www2.bmo.com $/$ bmo/files/images $/ 7 / 1 /$ knowledge_is_power.pdf

Sharma, P., Pisharodi, L., Moore, L.,Weiser, J. (2005). Crossing the great Divide: Understanding the mental health needs of South Asian youth. Report prepared by East Metro Youth Services, commissioned by the Ministry of Children and Youth Services. Retrieved October 2006 from http://www.emys.on.ca/media/pdf/Crossing the\%20Great Divide.pdf

Singla, R. (2005). South Asian Youth in Scandinavia: Inter-ethnic and intergenerational relationships. Psychology \& Developing Societies, 17(2). 215-235.

Smith, P., \& Riley, A. (2009). Cultural Theory: An Introduction. Oxford: Blackwell Publishing.

Schatzman, L., \& Strauss, A. L. (1973). Field research; strategies for a natural sociology. Englewood Cliffs, NJ: Prentice Hall.

Stanley, S. \& Okazaki, S. (1990). Asian-American Educational Achievements; A phenomenon in search of an explanation. American Psychologist, 45 (8), 913-920.

Statistics Canada. (2003). Ethnic Diversity Survey: portrait of a Multicultural Society. (Catalogue no. 89-593XIE2003001). Ottawa: Statistics Canada.

Statistics Canada. (2005). Population projections of Visible Minority Groups. Canada, Provinces and Regions, 2001 to 2017. (Catalogue no. 91-541-XIE2005001). Ottawa: Statistics Canada.

Statistics Canada. (2007). 2006 community profiles: 2006 Census. (Catalogue No. 92-591-XWE). Ottawa: Statistics Canada.

Statistics Canada. (2008). Group differences in educational attainment among the children of immigrants. (Catalogue No.11F0019M, no.308). Ottawa: Statistics Canada.

Talbani, A. S. (1991). Educational and ethnic minorities in Canada: South Asian students in Quebec schools (Doctoral Dissertation, McGill University, 1991).

Taylor, C. (1992). Multiculturalism and the Politics of Recognition: An Essay, Princeton, New Jersey: Princeton University Press.

Taylor, A., \& Krahn, H. (2005) "Resilient teenagers: explaining the high educational aspirations of visible minority immigrant youth in Canada," Journal of International Migration and Immigration, 6 (3), 405-434.

Tyyska, V. (2008). "Parents and Teens in Immigrant Families: Cultural influences and material pressures" Canadian Diversity, 6(2), 79-82.

Wadhwani, Z. (1999). To Be or Not To Be: Suicidal Ideation in South Asian Youth (Unpublished master's thesis). McGill University, Montreal, Quebec.

Winnicott, D. (1967). The Location of Cultural Experience. International Journal of Psychoanalysis, 48, 368372

Wortley, S. (2004). "Urban Youth Gangs in Canada: Results from Two Toronto-Area Research Projects" Presentation at Metropolis Presents Seminar on "Diverse Youth and the Law: Moral Panic or Critical Policy Problem" Ottawa, 22 January.

Yeh, C. J., \& Inose, M. (2002). Difficulties and coping strategies of Chinese, Japanese, and Korean immigrants students, Adolescence, 37, 69-82.

Zhou, M., \& Xiong, Y.S. (2005). The multifaceted American experiences of the children of Asian immigrants: Lessons for segmented assimilation. Ethnic and Racial Studies, 28(6), 1119-1152.

Ratna Ghosh is James McGill Professor and William C. Macdonald Professor of Education at McGill University. Her research interests focus on issues related to diversity and discrimination. She can be contacted at ratna.ghosh@mcgill.ca

Jaswant Guzder is Head of Psychiatry in the Center for Child Development and Mental Health Institute of Community and Family Psychiatry of McGill University. She can be contacted at jaswant@,videotron.ca. 